\title{
Endodontic success score in single session: brief review
}

\begin{abstract}
Introduction: The constant technological advance in the area of development and manufacture of equipment and instruments has allowed the accomplishment of endodontic treatments in less time. This technical agility is counteracted by a biological need where a shorter time exposure of the root canal to the auxiliary chemicals may compromise the success of endodontic treatment.
\end{abstract}

Objective: to review the success rate of endodontic treatments performed in a single session.

Methods: Experimental and clinical studies were included (case reports, retrospective, prospective and randomized trials) with qualitative and or quantitative analysis. The words were included "Endodontics," "Single Session Treatment," "Technological Advances".

Conclusion: the data presented showed that endodontic treatment in a single session, when it was performed in a single session, when well indicated and executed, has a high success rate.

Keywords: endodontics, single session treatment, technological advances
Volume 9 Issue 3 - 2018

\author{
Jennie Roxanna Allen Revoredo,' Clifford A \\ Allen, ${ }^{1,2}$ Idiberto José Zotarelli Filho' \\ 'University Center North Paulista (UNORP), Brazil \\ ${ }^{2}$ Departamento Dentistry, Clínica Angloamericana, Peru
}

Correspondence: Idiberto José Zotarelli Filho, Unipos, Post graduate and continuing education, Street Ipiranga, 3460, São José do Rio Preto SP, I5020-040, Brazil, Tel +55(17) 981666537/+55(I7)98803-7459, Email m.zotarelli@gmail.com

Received: April 25, 2018| Published: May II 2018

\section{Introduction}

Endodontic treatment aims to promote an environment conducive for the body to perform the repair of the periapical tissues after the therapeutic intervention, allowing the tooth to return to its functions. To reach this objective, it is necessary to establish cleaning and conformation for disinfection of root canal systems, filling and coronary sealing. ${ }^{1-3}$ With the evolution of the instrumentation systems, it was possible to simplify and enable the Endodontic treatment to be finalized in the same query in which it was started. ${ }^{2,3}$ Even so, several researchers have doubts about the antimicrobial efficacy achieved in single-session treatment, which has generated controversy over which procedures to use, single session or multiple sessions. ${ }^{3,4}$ The constant technological advance in the area of development and manufacture of equipment and instruments has allowed the accomplishment of endodontic treatments in less time. This technical agility is countered by a biological need where a shorter time exposure of the root canal to the auxiliary chemicals may compromise the success of endodontic treatment. ${ }^{4,5}$ There is still among the professionals a question about the influence of the treatment in a single session on the success of endodontic therapy. According to Leonardo et al. ${ }^{6}$ Endodontic failure is linked to the presence of microorganisms within the root canal system due to an inadequate sequence of work, incorrect instrumentation and irrigation, or poor filling. The main criteria for endodontic treatment in a single session are pulp necrosis and retreatments without symptomatology or periradicular lesion, and teeth with living pulp can be treated in a single session. ${ }^{1-4}$ Therefore, the objective of this study was to review the success rate of endodontic treatments performed in a single session.

\section{Methods}

Experimental and clinical studies were included (case reports, retrospective, prospective and randomized trials) with qualitative and or quantitative analysis. Initially, the key words were determined by searching the DeCS tool (Descriptors in Health Sciences, BIREME base) and later verified and validated by MeSh system (Medical Subject Headings, the US National Library of Medicine) in order to achieve consistent search.

\section{Mesh terms}

The words were included "Endodontics", "Single Session Treatment", "Technological Advances", "Further information", "the previous maxilla" description for refinement was added during searches and Google Scholar. It was stipulated deadline, and the related search covering all available literature on virtual libraries.

\section{Series of articles and eligibility}

A total of 35 articles were found involving endodontic and single session treatment. Initially, it was held the exclusion existing title and duplications in accordance with the interest described this work. After this process, the summaries were evaluated and a new exclusion was held. A total of 20 articles were evaluated in full, and 14 were included and discussed in this study (Figure 1).

\section{Literature review}

Endodontic in a single session, to reach the current state of development, went through several evolutionary phases, undergone radical modifications, according to the knowledge of each phase. Currently, it is understood that the success of endodontic treatment in a single session is directly associated with several factors that are related as if they were links of a chain, and that if one of them breaks, the probability of success of the treatment decreases sensibly. ${ }^{1-4}$ These factors are: precise diagnoses, maintenance of the aseptic chain, knowledge of the dental anatomy, correct chemical-mechanical preparation, adequate use of medications, hermetic fillings of the 
root canal system and preservation. ${ }^{4}$ They converge to a crucial point, which is contamination of the root canal system, which should be prevented in cases of biopulpectomy and eliminated in cases of necropulpectomies 5. In single-session treatments, it is believed that infection control, through cleansing, conformation and obturation with gutta-percha and antiseptic cements, would be sufficient to achieve success in the treatment, besides indisputably securing less time to reestablish the Functions of the dental element and its aesthetics., The followers of the treatment in multiple sessions believe in the necessity of intracanalar medication between sessions, with the objective to potentiate the disinfection obtained during the chemicalmechanical preparation, for a better postoperative and index of greater success in the prevention and repair of periradicular pathologies. ${ }^{6,7}$ The single session has been a more effective alternative than the multiple session, especially in communities where the patient usually misses after the first consultation when the pain was attenuated. ${ }^{8}$ With the evolution of Endodontics, new instrumentation systems were discovered, namely Nickel-Titanium rotary instrumentation systems. ${ }^{9}$ These new mechanized instrumentation systems have revolutionized Endodontics because they have made mechanical instrumentation much simpler for clinicians, thus making the instrumentation and conformation of the root faster and with greater probability of the clinical act being finalized in the same consultation in which Was started $^{10-13} \mathrm{~A}$ research was also conducted among the directors of endodontic graduate programs in the USA, in order to evaluate the overall opinion regarding endodontic therapy in a single session. The results indicated that single-session endodontic therapy is being more taught and practiced than is evident in the literature. ${ }^{4}$ Another study affirms that the most important for achieving success is not the number of Sessions, but rather a well-executed technique with the professional conscience to satisfactorily perform the cleaning, disinfection, preparation and filling of root. ${ }^{5}$ Others emphasize that when the pulp tissue is removed, an inflammatory reaction occurs in the apical periodontal tissue, constituting an initial stage of the repair process, which occurs 48 hours after the intervention, and there is no bacterial activity. ${ }^{6}$ Those who advocate treatment in a single session justify that in a second session, procedures, however careful they may be, may trigger a new inflammatory reaction in response to trauma in repaired and rested tissues. ${ }^{6}$ Also, the option for immediate root canal filling in cases of living pulp, after instrumentation, if there is time to perform the procedure. It should be noted that the single session treatment modality is based on the fact that the channel is free of bacteria. ${ }^{7}$ As long as aseptic chain has been maintained by the professional, there is no reason not to complete the treatment in a single session, even in case of symptomatic irreversible pulpitis. However, when percussion symptomatology occurs, because acute apical periodontitis is associated with pulpitis, treatment should be postponed. For cases of pulpal necrosis, the author advises for mediate treatment. ${ }^{7}$ The endodontic treatment in a single session, and stress that the treatment of root canals is directly related to the control of endodontic infection, to be successful. ${ }^{8}$ It is said that it is undeniable indeed that the treatment performed in a single session brings benefits to both the patient and the professional, such as: saving time; Material economy; You do not need to re-familiarize yourself with the anatomy of the canal. They cite as disadvantages in patients with temporomandibular dysfunction; And symptomatic exacerbation. ${ }^{8}$ The criteria for selecting possible cases of endodontic treatment in a session are: accept the treatment plan in a positive way, do not present acute symptoms, no exudate or hemorrhages that do not stop draining, no anatomical interference such as the existence of fine root, Curved or even calcified, cases where there is the necessary consultation time to finish the treatment and cases that are simple, that is, there can be no steps, blocks or perforations. ${ }^{9}$ Within this vast group, there are cases that are even indicated to be solved in a session, such as: vital teeth, teeth with anterior fractures located in regions that interfere with aesthetics, special patients, where it is necessary to be sedated in all procedures, Patients who are unhealthy and due to their weakness need antibiotic prophylaxis and patients with motor disabilities or other morbidity that makes it impossible for them to attend the appointments with some frequency. ${ }^{9}$

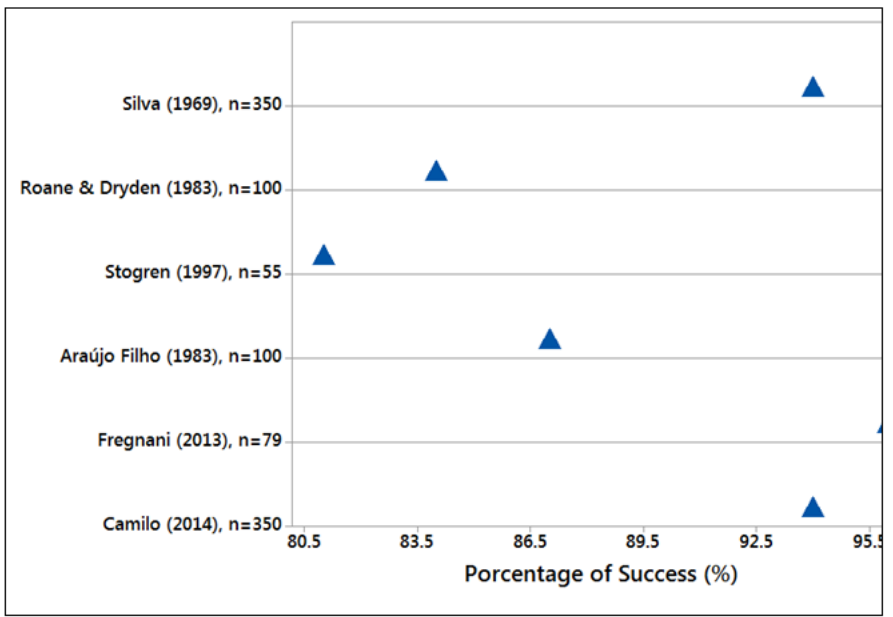

Figure I Graph showing a successful endodontic treatment score in a single session throughout the dental history, with $\mathrm{p}<0.05$, with statistical significance among all the literary findings.

In recent years, clinicians have been observing and monitoring an enormous evolution in endodontics. ${ }^{6,7}$ The continuous training of professionals is essential, both in terms of techniques and the manipulation of new materials. Several factors play an important role in the decision to perform endodontic treatment in single or multiple sessions. ${ }^{6-8}$ Based on the results obtained in my review, it seems that the procedure that will be implemented more frequently, is the endodontic treatment performed in a single session. In most studies where comparisons are made between single session and multiple sessions the investigators report that a statistically significant difference in cure improvement was expected in procedures performed in multiple sessions. ${ }^{3-6}$ However, in most studies, these results are not statistically significant, thus making treatment prolongation unnecessary, which would cause more discomfort to the patient. Providing extremely rigorous chemical and mechanical preparation and effective instrumentation and irrigation, the success of endodontic in a single session will be ensured. ${ }^{5-7}$ What is more important to achieve success is not the number of sessions but a well executed technique, adequately performing the cleaning, disinfection, preparation of the root canals and the filling of the root canal. ${ }^{7}$ The endodontic treatment, whether it is advocated in one or multiple sessions, should always aim at the complete removal of pulp tissue and provide optimum conditions for root canal filling. ${ }^{1}$

\section{Conclusion}

The data presented showed that endodontic treatment in a single session, when well indicated and performed, shows a high success rate, around $90.0 \%$ to $99.0 \%$. 


\section{Acknowledgments}

None.

\section{Conflict of interest}

The authors declare that there is no conflict of interest.

\section{References}

1. Humonen S, Suominen AL, Vehkalahti MM. Prevalence of apical periodontitis in root filled teeth: findings from a nationwide survey in Finland. Int Endod J. 2016;50(3):229-236.

2. Leonardi Dutra K, Haas L, Porporatti AL, et al. Diagnostic accuracy of cone-beam computed tomography and conventional radiography on apical periodontitis: A systematic review and meta-analysis. $J$ Endod. 2016;42(3):356-64.

3. Alfouzan K, Baskaradoss JK, Geevarghese A, et al. Radiographic diagnosis of periapical status and quality of root canal fillings in a Saudi Arabian subpopulation. Oral Health Prev Dent. 2016;14(3):241-8.

4. Di Filippo G, Sidhu SK, Chong BS. Apical periodontitis and the technical quality of root canal treatment in an adult sub-population in London. $\mathrm{Br}$ Dent J. 2014;216(10):E22.

5. Oginni AO, Adeleke AA, Mejabi MO, et al. Risk factors for apical periodontitis in a Nigerian suburban adult population. Niger Postgrad Med J. 2015;22(2):105-9.
6. Leonardo MR. Orientação clínica da disciplina de endodontia da Faculdade de Farmácia e Odontologia de Araraquara com relação ao tratamento endodontico. Revista Brasileira de Odontologia. 1969;26:139-151.

7. Berlinck T, Tinoco JM, Carvalho FL, et al. Epidemiological evaluation of apical periodontitis prevalence in an urban Brazilian population. Braz Oral Res. 2015;29:51.

8. Archana D, Gopikrishna V, Gutmann JL, et al. Prevalence of periradicular radiolucencies and its association with the quality of root canal procedures and coronal restorations in an adult urban Indian population. $J$ Conserv Dent. 2015;18(1):34-8.

9. Silva HF. Desinfecção e obturação dos canais radiculares infectados, em unica única sessão. Rev paul Odont. 1969;8:2:20-23.

10. Roane JB, Dryden JA, Grimes EW. Incidence ofpostoperative pain afier single and multiple procedures. Oral Surgery, Oral Medicine, Oral Pathology. 1983:68-72.

11. Araújo filho W, Cabreira M, Costa F. Tratamento endodôntico em sessão única: levantamento de opinião de endodontistas da cidade do Rio de Janeiro. RBO. 2003;60(2).

12. Stogren. Canais radiculares em unica sessão. Edição 1. Fregnani E, Edição: 1ª/2013; 1997.

13. Camilo Am. Avaliação da Sintomatologia pós operatória em tratamentos endodontcos potência e ampliação do forame apical. Campinas: Centro de pesquisas odontólogica São Leopoldo Mandic; 2014. 